\title{
Structural Analysis of Hydrolytic Condensed Zirconium Oxide by the Anomalous X-ray Scattering Method
}

\author{
Kazumasa SUGIYAMA, Yoshio WASEDA and Setsuko KUDO
}

Research Institute of Mineral Dressing and Metallurgy, Tohoku University, Katahira, Aoba-ku, Sendai, Miyagi-ken, 980 Japan.

(Received on May 2, 1991; accepted in final form on July 26, 1991)

\begin{abstract}
The anomalous $X$-ray scattering (AXS) technique has been applied to obtain the environmental radial distribution function (RDF) around a zirconium in amorphous $\mathrm{ZrO}_{2}$ prepared by hydrolytic condensation of zirconium alkoxide. The environmental RDF was determined from the intensities measured at the $\mathrm{Zr} K$ absorption edge using synchrotron radiation and compared with the ordinary RDF. By combining the environmental and ordinary RDFs of amorphous $\mathrm{ZrO}_{2}$, zirconium is quantitatively confirmed to be surrounded by six oxygens at a distance of $0.214 \mathrm{~nm}$ and a considerably distorted $\mathrm{ZrO}_{6}$ octahedron is likely to exist as a fundamental local ordering unit structure. A possible structural model of amorphous $\mathrm{ZrO}_{2}$ in near neighbour region has also been proposed.
\end{abstract}

KEY WORDS: amorphous zirconia; radial distribution function; anomalous $X$-ray scattering; synchrotron radiation.

\section{Introduction}

The sol-gel method using metal alkoxides and other metal organic compounds as master materials has been extensively developed for making various advanced materials such as fine oxide powders, glasses and ceramic bodies and substrates with various superior properties. ${ }^{1)}$ The advantages of this relatively new method may be explained as follows. The final products can be obtained by heating at relatively low temperature, because these master materials are highly reactive and the uniform mixing is likely obtained for multicomponent systems. Moreover it is quite interesting to make various kinds of amorphous materials which cannot be prepared by the conventional melt quenching technique.

A number of interesting materials have been prepared by this sol-gel method. Zirconium oxide is included in this category and the thermal decomposition of amorphous $\mathrm{ZrO}_{2}$ formed from zirconium alkoxides ${ }^{2,3}$ ) and zirconium salts ${ }^{4,5)}$ are known to produce a metastable tetragonal $\mathrm{ZrO}_{2}\left(t-\mathrm{ZrO}_{2}\right)$, in addition to monoclinic $\mathrm{ZrO}_{2}\left(m-\mathrm{ZrO}_{2}\right)$ which is actually stable under about $1273 \mathrm{~K}$. However, the formation of $t-\mathrm{ZrO}_{2}$ at low temperature is still one of controvertial subjects in the following results. Cypres et $a l^{6)}$ and other two research groups ${ }^{7,8)}$ proposed that the stabilization of $t-\mathrm{ZrO}_{2}$ is attributed to various anionic impurities such as $\mathrm{OH}^{-}$, whereas Garvie ${ }^{4)}$ and some other people ${ }^{2,9)}$ suggest that it should be rather related to the particle size effect. According to Livage et al. ${ }^{9)}$ and Tani et $a l .{ }^{10)}$ the stabilization of the tetragonal form of $\mathrm{ZrO}_{2}$ may be explained by the similarity of local ordering structure between amorphous and crystalline tetragonal $\mathrm{ZrO}_{2}$. Garvie and Mitsuhashi et al. ${ }^{11)}$ also pointed out the significance of strain on the stabilization of $t-\mathrm{ZrO}_{2}$. In these contexts, the structure of amorphous $\mathrm{ZrO}_{2}$ holds the key to give the conclusive remark regarding its particular crystallization behavior by low temperature heating. However, the quantitative accuracy of the presently available structural data of amorphous $\mathrm{ZrO}_{2}$ was not sufficient to allow the definite comment on the structural similarity in comparison with those of crystalline $\mathrm{ZrO}_{2}$ phases.

It is well known that the coordination numbers in disordered systems can be obtained from the radial distribution function (RDF) data using X-ray diffraction and such data provide a convenient picture of their local structure in near-neighbour region. The so-called pair function method by Mozzi and Warren ${ }^{12}$ is one of the convenient procedures to estimate the interatomic distances and coordination numbers of a system containing more than two kinds of atoms, such as silicate glasses. On the other hand, Narten ${ }^{14)}$ determined the structural parameters of silicate glass using the leastsquares technique by calculating the intensity profiles and the results were found to be similar to those reported by Mozzi and Warren. ${ }^{12)}$

The atomic correlations of the individual chemical constituents around a specific element are strongly required in order to describe the fine structure in multi-component systems. For these requirements, the relatively new method of anomalous X-ray scattering technique (hereafter referred to as AXS) is recently received much attention and its usefulness to determine the environmental structure around a specific element 
in multi-component systems has been well demonstrated. ${ }^{13)}$ The structural analysis of the present interest of zirconium oxide requires more parameters than those determined from the single diffraction data alone and this prompts us to apply the least-squares method to the differential intensity profile obtained from the AXS measurements.

The main purpose of this work is to present our recent results for determining the atomic structure of hydrolytic condensed zirconium oxide at longer distance as well as the structure in the nearest-neighbor region including the AXS experiments of the differential intensity measurements.

\section{Experimental}

The $0.1 \mathrm{~mol} / \mathrm{dm}^{3}$ solution of the zirconium tetra- $n$ butoxide was prepared by dissolving $\mathrm{Zr}\left(\mathrm{OC}_{4} \mathrm{H}_{9}\right)_{4}$ in $n$-butyl alcohol. This solution was then mixed with $\mathrm{H}_{2} \mathrm{O} / n$-butyl alcohol mixture $\left(\mathrm{H}_{2} \mathrm{O}=10 \mathrm{vol} \%\right)$ so as to give final molar ratio; $\mathrm{H}_{2} \mathrm{O} / \mathrm{Zr}\left(\mathrm{OC}_{4} \mathrm{H}_{9}\right)_{4}$ to be 6.0 and preliminary drying was made by rotary evaporator. Thus resultant condensed material was dried at $423 \mathrm{~K}$ for three hours. The details of sample preparation are almost identical to those reported by Saito et al. ${ }^{15)}$ This material was annealed at various temperatures from 423 to $823 \mathrm{~K}$ for $30 \mathrm{~min}$ and they were examined by the ordinary X-ray diffraction method using $\mathrm{Cu} K \alpha$ radiation. Typical $\mathrm{X}$-ray diffraction patterns are given in Fig. 1 using the results of original and two annealed samples, where $2 \theta$ is the scattering angle. Up to $573 \mathrm{~K}$, only hallow patterns were obtained. Whereas the crystallization of such amorphous sample so as to produce $t-\mathrm{ZrO}_{2}$ was detected with the increment of annealing temperature. At higher temperature such as $1373 \mathrm{~K}$, only $m-\mathrm{ZrO}_{2}$ remained. It may be noted that the diffraction peaks of $t-\mathrm{ZrO}_{2}$ obtained in this work agree well with the JCPDS cards of No. 24-1164.

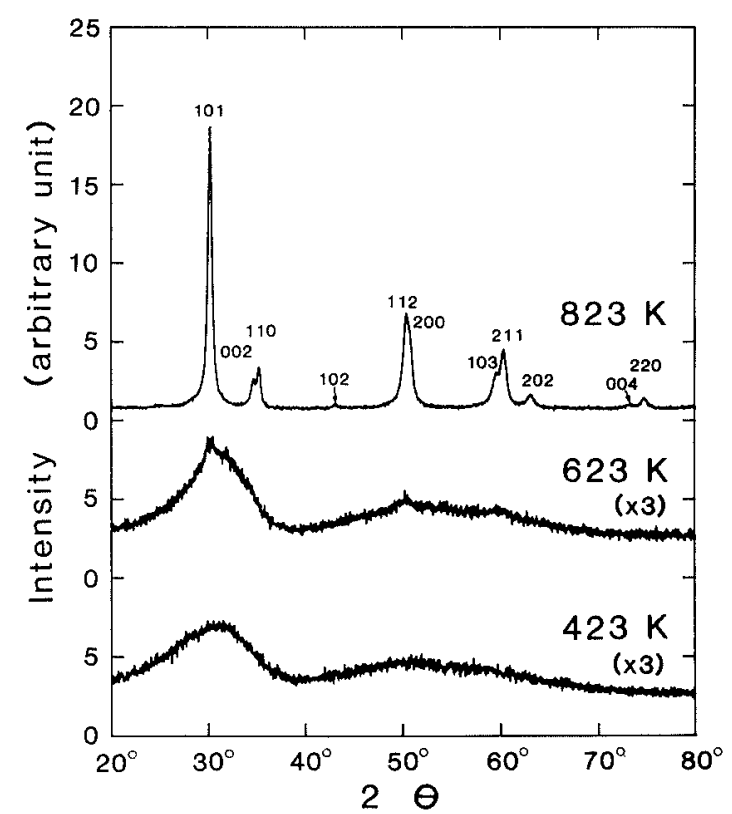

Fig. 1. X-ray diffraction patterns of amorphous $\mathrm{ZrO}_{2}$ annealed at different temperatures by $\mathrm{Cu} K \alpha$ radiation.
On the basis of these experimental facts, a sample was prepared by annealing at $573 \mathrm{~K}$ in an oxygen atmosphere for further structural investigation. This sample was found to contain at most 4.0 mass $\%$ of volatile species such as water and alcohol, from the estimation by the thermal gravimetric analysis. No further consideration of such volatile components was taken into account in the following analysis. The sample density was measured by the Archimedes method with toluene using the samples pressed in the shape of pellet.

A beam line (6B station) in the Photon Factory, National Laboratory for High Energy Physics, Tsukuba, Japan, where a double Si (111) crystal monochromator is provided upstream, was used for the present AXS measurements. The incident beam is monitored by an $\mathrm{N}_{2}$ gas ion chamber placed in front of the sample, so as to keep the total number of the photon irradiating the sample constant. The fluorescent radiation from the sample, mainly arising from the tail of the band pass and the higher harmonic diffraction of the monochromator crystal is frequently not negligible, even if an energy below the absorption edges is used for the measurements like in the present case. Thus, the pure intrinsic germanium solid state detector was employed in order to separate such fluorescent component from the scattered intensity. Details of the experimental setting is given in Ref. 13).

The intensity profiles were measured at energies of 17.973 and $17.698 \mathrm{keV}$, which correspond to 25 and $300 \mathrm{eV}$ below the $\mathrm{Zr} K$ absorption edge $(17.998 \mathrm{keV})$. Then, these intensities were corrected for absorption and converted to the absolute intensities by the generalized Krogh-Moe-Norman method, ${ }^{16)}$ including the correction for Compton scattering. ${ }^{17)}$ The detected energy dependence of intensity results mainly from the variation of the real part of the anomalous dispersion terms of a zirconium atom, $f_{\mathbf{Z}_{\mathbf{r}}}^{\prime}{ }^{18)}$ Therefore the resultant intensity difference, $\Delta i(Q)$, may be given by the following equation;

$$
\begin{aligned}
& \Delta i(Q)= \frac{\left(I_{300}(Q)-\left\langle f_{300}^{2}\right\rangle\right)-\left(I_{25}(Q)-\left\langle f_{25}^{2}\right\rangle\right)}{c_{\mathrm{Zr}}\left(f_{\mathrm{Zr} 300}^{\prime}-f_{\mathrm{Zr} 25}^{\prime}\right) W(Q)} \\
&= \int_{0}^{\infty} 4 \pi r^{2} \sum_{j=1}^{2} \frac{\operatorname{Re}\left[f_{j 300}(Q)+f_{j 25}(Q)\right]}{W(Q)} \\
& \times\left(\rho_{\mathrm{Zrj}}-\rho_{o j}\right) \frac{\sin (Q r)}{Q r} d r \\
& W(Q)=\sum_{j=1}^{2} c_{j} \operatorname{Re}\left(f_{j 300}(Q)+f_{j 25}(Q)\right)
\end{aligned}
$$

where $Q=4 \pi \sin \theta / \lambda$ is the wave vector and $I(Q)$ the absolute intensity, $c_{\mathrm{Zr}}$ the atomic fraction of zirconium, $f_{j}$ the X-ray atomic form factor of the $j$-th element, ${ }^{19)}$ $\left\langle f^{2}\right\rangle$ the mean square of the atomic scattering factors, $\rho_{\mathrm{Zrj}}$ the number density function of the $j$-th atom around a zirconium, and $\rho_{o j}$ the average number density for $j$-th element. " $R e$ " indicates the real part of the value in the parentheses. The subscripts 25 and 300 for $I(Q)$ represent the incident energies corresponding to 25 and $300 \mathrm{eV}$ below the $\mathrm{Zr} K$ absorption edge; 17.973 and 
$17.698 \mathrm{keV}$, respectively. The summation in the above equation indicates the sum over the constituents of the present samples. The environmental RDF for $\mathrm{Zr}$, which represents the local atomic distribution around a zirconium can be obtained by the Fourier transformation of the quantity $Q \Delta i(Q)$;

$$
4 \pi r^{2} \rho_{\mathrm{Zr}}(r)=4 \pi r^{2} \rho_{0}+\frac{2 r}{\pi} \int_{0}^{\infty} Q \Delta i(Q) \sin (Q r) d Q
$$

$\rho_{0}$ in Eq. (3) is the average number density of atoms in a system.

On the other hand, the so-called reduced interference function $i(Q)$ from the absolute intensity $I(Q)$ in the following form,

$$
i(Q)=\left(I(Q)-\left\langle f^{2}\right\rangle\right) /\langle f\rangle^{2}
$$

where $\langle f\rangle$ is the average atomic scattering factor. By Fourier transformation of the function $Q i(Q)$, the ordinary RDF can be estimated:

$$
4 \pi r^{2} \rho(r)=4 \pi r^{2} \rho_{0}+\frac{2 r}{\pi} \int_{0}^{\infty} Q i(Q) \sin (Q r) d Q
$$

where $\rho(r)$ is the so called average number density distribution function.

\section{Results and Discussion}

The two scattering intensity profiles measured at two energies close to the $\mathrm{Zr} K$ absorption edge are shown in Fig. 2, where the differential intensity profile is also given at the top. The environmental interference functions $Q \Delta i(Q)$ of the present sample was estimated and shown in Fig. 3. The ordinary interference function $Q i(Q)$ calculated from the diffraction experiment of single energy of $17.698 \mathrm{keV}$ is also illustrated in Fig. 3 for comparison. The profiles of these interference functions consist of the first peak at about $22 \mathrm{~nm}^{-1}$ followed by a

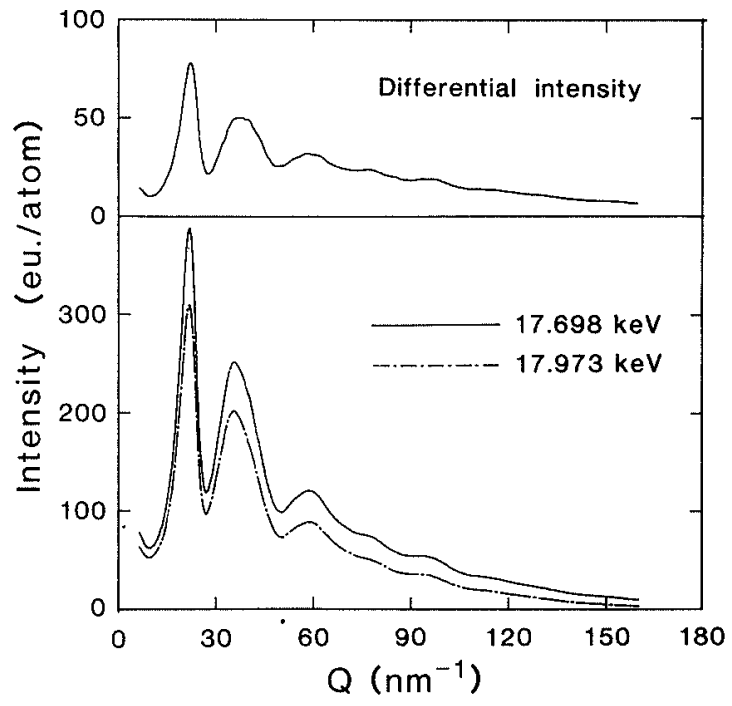

Fig. 2. Differential intensity profiles of amorphous $\mathrm{ZrO}_{2}$ (top) obtained from the intensity data (bottom) measured at incidence energies of 17.973 and $17.698 \mathrm{keV}$, which correspond to energies 25 and $300 \mathrm{eV}$ below the $\mathrm{Zr} K$ absorption edge. number of peaks, which indicate a considerable fraction of local ordering unit structures exist in this glass structures although their distribution appears to be no long range ordering. These features contrast to the case of metallic glasses, where the rapid damping of interference function is clearly observed.

The environmental and ordinary RDFs were calculated from the interference functions of Fig. 3 using Eqs. (3) and (5), respectively, and they are given in Fig.

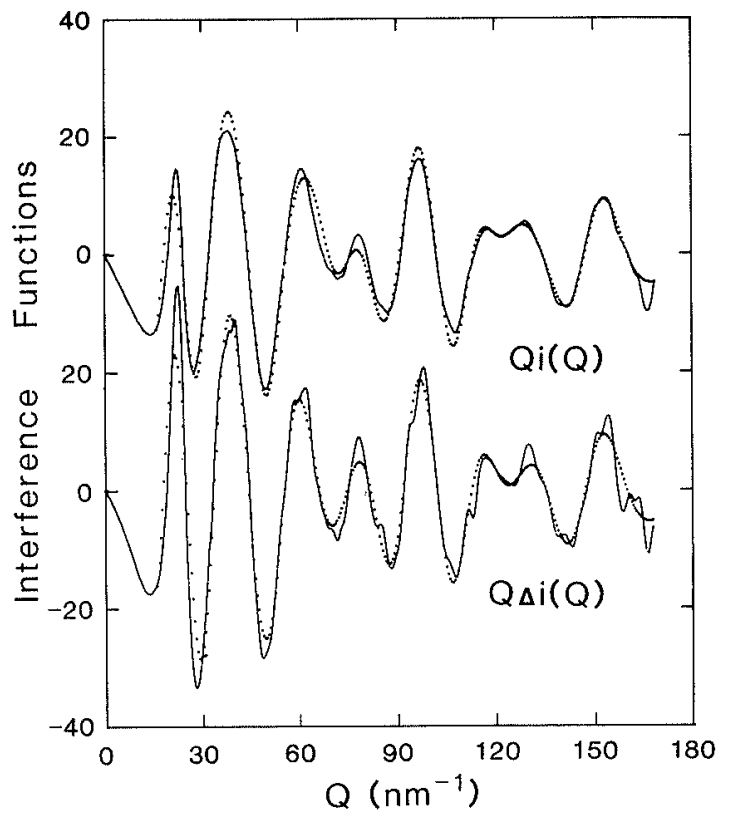

Fig. 3. (Top) Interference function of amorphous $\mathrm{ZrO}_{2}$ obtained from the intensity measurement at the energy of $17.698 \mathrm{keV}$. (Bottom) Environmental interference functions $Q \Delta i(Q)$ for zirconium of amorphous $\mathrm{ZrO}_{2}$ obtained from the intensity data measured at energies close to the $\mathrm{Zr} K$ absorption edge.

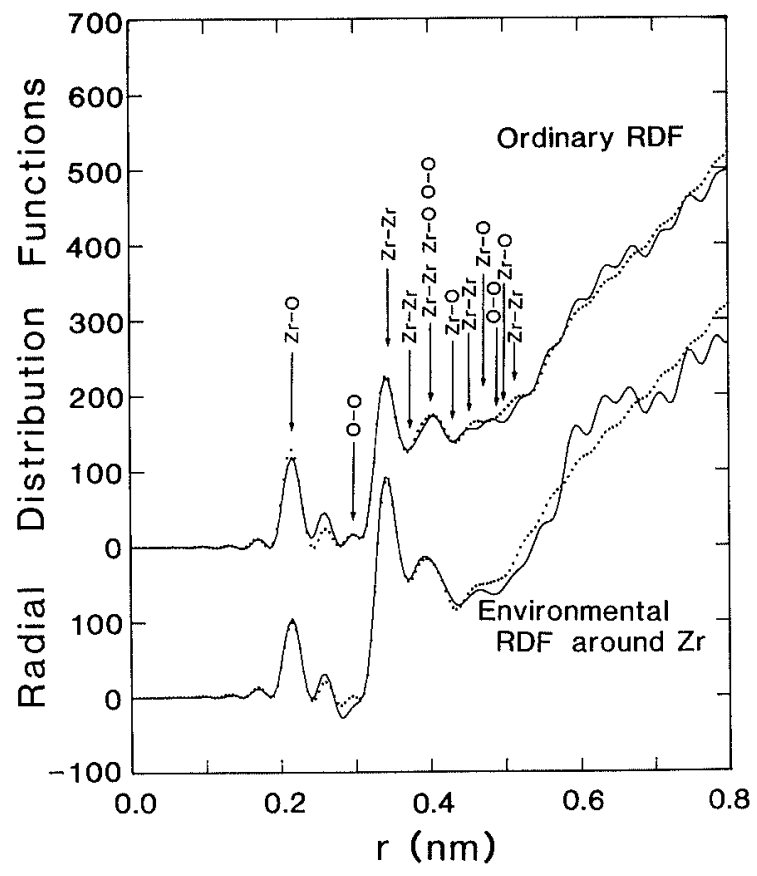

Fig. 4. Ordinary radial distribution function $4 \pi r^{2} \rho(r)$ and environmental radial distribution functions $4 \pi r^{2} \rho_{\mathrm{Zr}}(r)$ calculated from the interference functions of Fig. 3 . 
4. In this work, the observed intensity data at $Q$ less than $9 \mathrm{~nm}^{-1}$ were smoothly extrapolated to zero at $Q=0 \mathrm{~nm}^{-1}$. The effect of the extrapolation or the truncation up to $Q=168 \mathrm{~nm}^{-1}$ is known to make no critical contribution to the RDFs of a glassy sample calculated from the interference functions consisting of the broad peaks only in such Fourier method. ${ }^{20}$ Since the atoms do not approach one another inside the atomic diameter, the calculated RDFs should be zero in the small $r$ region below the nearest-neighbor peak. Therefore the interference functions given in this work include a correction considering the experimental uncertainty so as to remove such spurious oscillations of the RDFs in the small $r$ region by the usual method. ${ }^{16,21)}$

The ordinary RDF corresponds to the sum of three partial $\mathrm{RDF}$ of $\mathrm{Zr}-\mathrm{O}, \mathrm{Zr}-\mathrm{Zr}$ and $\mathrm{O}-\mathrm{O}$. From the information of ionic radii of the constituent elements, the first peak around 0.22 and $0.34 \mathrm{~nm}$ can be suggested to be $\mathrm{Zr}-\mathrm{O}$ and $\mathrm{Zr}-\mathrm{Zr}$ pairs, respectively. The peak around $0.37 \mathrm{~nm}$ may be attributed to the mixed correlations of the $\mathrm{Zr}-\mathrm{Zr}, \mathrm{Zr}-\mathrm{O}$ and $\mathrm{O}-\mathrm{O}$ interactions. It is worth mentioning in the ordinary RDF that the $\mathrm{Zr}-\mathrm{Zr}$ pair around $0.34 \mathrm{~nm}$ is well coincident with the atomic pairs characterized by the $m-\mathrm{ZrO}_{2}$ structure. Therefore, the fundamental local structure of the present amorphous $\mathrm{ZrO}_{2}$ sample seems to be rather close to that of $m-\mathrm{ZrO}_{2}$ than the $t-\mathrm{ZrO}_{2}$ one. One the other hand, the $\mathrm{O}-\mathrm{O}$ atomic correlations are very difficult to ascribe in the present ordinary RDF, because of its low scattering power for X-ray compared to that of zirconium. Structural parameters of $\mathrm{Zr}-\mathrm{O}$ and $\mathrm{Zr}-\mathrm{Zr}$ pairs are likely to be obtained. However, the definite and precise information of the local atomic arrangements of amorphous $\mathrm{ZrO}_{2}$ cannot be determined as a unique solution from the present ordinary RDF data alone. This is particularly true in the higher order correlations, because more than two kinds of atomic pairs usually overlap at longer distances.

As shown in Fig. 4, the structural features observed in the environmental RDF for zirconium is essentially similar to those of ordinary RDF of amorphous $\mathrm{ZrO}_{2}$, although the environmental RDF includes only the atomic correlations of $\mathrm{Zr}-\mathrm{O}$ and $\mathrm{Zr}-\mathrm{Zr}$ pairs. This is mainly due to the reason that the contribution of $\mathrm{O}-\mathrm{O}$ pairs to the ordinary RDF is not so significant. Nevertheless, it is worth mentioning that the correlation of $\mathrm{Zr}-\mathrm{Zr}$ pairs in the environmental RDF is rather distinct at the distance of $0.34 \mathrm{~nm}$, compared to that of the ordinary RDF. When such valuable different nature observed in the environmental RDF using present AXS technique is coupled with the ordinary RDF data, the resolution of the structural parameters for $\mathrm{Zr}-\mathrm{O}$ and $\mathrm{Zr}-\mathrm{Zr}$ pairs can be improved even in the higher order correlations. The following data processing was made along this data. The coordination number of $\mathrm{Zr}-\mathrm{O}, \mathrm{Zr}-$ $\mathrm{Zr}$ and $\mathrm{O}-\mathrm{O}$ pairs estimated in this work by applying the least-square technique suggested by Narten ${ }^{14)}$ to the interference function. According to Narten, the reduced interference function $i(Q)$ may be given by the expression

$$
\begin{aligned}
i(Q)= & {\left[\sum_{i=1}^{m} \sum_{k} N_{i k} \exp \left(-b_{i k} Q^{2}\right) f_{i} f_{k} \frac{\sin Q r_{i k}}{Q r_{i k}}\right.} \\
& +\sum_{\alpha=1}^{m} \sum_{\beta=1}^{m}\left[\exp \left(-b_{\alpha \beta}^{\prime} Q^{2}\right) f_{\alpha} f_{\beta} 4 \pi \rho_{0}\right. \\
& \left.\left.\times\left(Q r_{\alpha \beta}^{\prime} \cos Q r_{\alpha \beta}^{\prime}-\sin Q r_{\alpha \beta}^{\prime}\right)\right] / Q^{3}\right] /\langle f\rangle^{2}
\end{aligned}
$$

where $m$ is the number of elements, $N_{i k}$ is the average number of type- $k$ atoms around any type- $i$ atom at the average distance of $r_{i k}$ and the value of $2 b_{i k}$ is the mean square variation. The quantities of $r_{\alpha \beta}^{\prime}$ and $b_{\alpha \beta}^{\prime}$ correspond to the mean and the variance of the boundary region which need not be sharp. ${ }^{14)}$ It may be also noted that the first and second terms of Eq. (6) represent the discrete Gaussian-like distributions and a continuous distribution with an average number density in the higher order correlations in the disordered system, respectively.

The quantities of $N_{i k}, r_{i k}$ and $b_{i k}$ for the nearest neighbor interactions were obtained by the least-squares calculation of Eq. (6) so as to reproduce the experimental interference function in Fig. 3. The differential interference function $Q \Delta i(Q)$ can be readily calculated by taking the difference of the calculated ordinary coherent intensity similarly estimated at the two energies in the AXS measurements using the Eqs. (1), (2) and (3) and compared with the experimental data of $Q \Delta i(Q)$ in Fig. 3. Thus, the resolution of the structural parameters can be improved at the reasonable lebel by the leastsquares variational technique using the experimental and theoretical interference functions of not only $Q i(Q)$ but also $Q \Delta i(Q)$.

The present analysis qualitatively suggests that the structural features of amorphous $\mathrm{ZrO}_{2}$ are rather close to those of $m-\mathrm{ZrO}_{2}$ than $t-\mathrm{ZrO}_{2}$ structure. Then, at the first step, the $22 \%$ random vacancy $m-\mathrm{ZrO}_{2}$ structure model based on the density measurements was applied, similar to the approach of $\mathrm{Narten}^{14)}$ for explaining the experimental RDF data. The converged structural parameters could not reproduce the experimental RDFs particularly, the RDF data in the distance of $0.37 \mathrm{~nm}$, which corresponds to first $\mathrm{Zr}-\mathrm{Zr}$ pairs in $t-\mathrm{ZrO}_{2}$ structure. It should also be kept in mind that the atomic configurations of amorphous $\mathrm{ZrO}_{2}$ are not exactly identical to those of $m-\mathrm{ZrO}_{2}$. Therefore, the $22 \%$ random vacancy model coupled with both $t-\mathrm{ZrO}_{2}$ and $m-\mathrm{ZrO}_{2}$ structures was used as initial parameters for the further calculation. After several italations, the interference functions drawn with dotted lines in Fig. 3 were obtained. The RDFs calculated by the Fourier transformation of these interference functions are also shown with dotted lines in Fig. 4. The resultant parameters are summarized in Table 1 together with the crystalline zirconium oxides. ${ }^{22,23)}$ According to the $\mathrm{O}-\mathrm{O}$ correlation, these parameters were fixed as suggested from $m-\mathrm{ZrO}_{2}$ with $22 \%$ random vacancy model because the contribution of the $\mathrm{O}-\mathrm{O}$ pairs are not significant as described above. Since that the variation of $r$ and 
Table 1. Structural parameters of the near neighbor correlations for amorphous $\mathrm{ZrO}_{2}$ determined in the present work.

\begin{tabular}{lcccccc}
\hline & \multicolumn{2}{c}{ Amorphous } & \multicolumn{2}{c}{ Monoclinic } & \multicolumn{2}{c}{ Tetragonal } \\
$\begin{array}{c}\text { Density } \\
\left(\mathrm{Mg} / \mathrm{m}^{3}\right)\end{array}$ & \multicolumn{2}{c}{4.47} & \multicolumn{2}{c}{5.74} & \multicolumn{2}{c}{5.86} \\
\hline$i-j$ pairs & $r(\mathrm{~nm})$ & $N$ (atom) & $r(\mathrm{~nm})$ & $N$ (atom) & $r(\mathrm{~nm})$ & $N$ (atom) \\
$\mathrm{Zr}-\mathrm{O}$ & $0.2 \mathrm{I} 4$ & 5.8 & 0.216 & 7.0 & 0.226 & 8.0 \\
$\mathrm{Zr}-\mathrm{O}$ & 0.395 & 2.3 & 0.385 & 8.0 & & \\
$\mathrm{Zr}-\mathrm{O}$ & 0.427 & 5.4 & 0.444 & 12.0 & 0.413 & 12.0 \\
$\mathrm{Zr}-\mathrm{O}$ & 0.465 & 6.3 & & & 0.448 & 12.0 \\
$\mathrm{Zr}-\mathrm{O}$ & 0.495 & 4.1 & 0.490 & 8.0 & & \\
$\mathrm{Zr}-\mathrm{Zr}$ & 0.341 & 4.4 & 0.347 & 7.0 & & \\
$\mathrm{Zr}-\mathrm{Zr}$ & 0.371 & 1.6 & & & 0.366 & 12.0 \\
$\mathrm{Zr}-\mathrm{Zr}$ & 0.398 & 2.5 & 0.415 & 3.0 & & \\
$\mathrm{Zr}-\mathrm{Zr}$ & 0.449 & 1.4 & 0.456 & 1.0 & & \\
$\mathrm{Zr}-\mathrm{Zr}$ & 0.509 & 2.1 & 0.524 & 6.0 & 0.519 & 6.0 \\
$\mathrm{O}-\mathrm{O}$ & & & & & 0.265 & 6.0 \\
$\mathrm{O}-\mathrm{O}$ & 0.296 & $7.4^{*}$ & 0.285 & 9.5 & & \\
$\mathrm{O}-\mathrm{O}$ & & & & & 0.344 & 8.0 \\
$\mathrm{O}-\mathrm{O}$ & 0.398 & $7.4^{*}$ & 0.394 & 9.5 & & \\
$\mathrm{O}-\mathrm{O}$ & & & & & 0.439 & 12.0 \\
$\mathrm{O}-\mathrm{O}$ & 0.486 & $4.3^{*}$ & 0.474 & 5.5 & & \\
\hline
\end{tabular}

* fixed

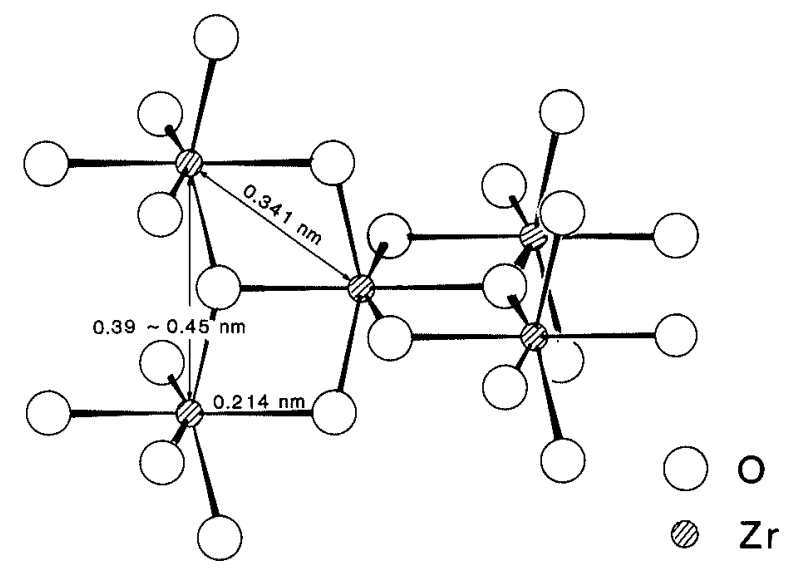

Fig. 5. Schematic diagrams of the atomic structure of amorphous $\mathrm{ZrO}_{2}$.

$N$ depend upon the initial structural model, the parameters in Table 1 should be read as not unique but possible solution with respect to the structure of amorphous $\mathrm{ZrO}_{2}$. For convenience, the interatomic distances obtained by the present analysis is shown by the arrows in Fig. $4 .{ }^{22)}$

The present results quantitatively indicate that the fundamental local ordering unit of amorphous $\mathrm{ZrO}_{2}$ investigated in this work is octahedrally coordinated zirconium and its distance is $0.214 \mathrm{~nm}$. About the first neighboring $\mathrm{Zr}-\mathrm{Zr}$ pairs, a zirconium is surrounded by about four zirconium at about $0.34 \mathrm{~nm}$ forming a particular structural unit. With these facts, a threedimensional structural model illustrated in Fig. $\mathbf{5}$ is proposed as one of the possible amorphous structures by considering the simple geometrical factors. This model indicates that the zirconium octahedra link each other with sharing four edges of coordination polyhedra. The other $\mathrm{Zr}-\mathrm{Zr}$ pairs ranging from 0.39 to $0.45 \mathrm{~nm}$ are also well attributed in this structural model, although
$\mathrm{Zr}-\mathrm{Zr}$ pairs at $0.37 \mathrm{~nm}$ can not be elucidated. Another structural model was suggested by Livage et al. ${ }^{9)}$ which is also feasible in the sight of the $\mathrm{Zr}-\mathrm{Zr}$ configuration except for its extraordinary bi-dimensional character. Present data could not allow to obtain the definite conclusion on the reliability of these two model.

Monomeric zirconium alkoxides are suggested to undergo hydrolysis condensation reaction to form the linear oxide alkoxide polymers in which $\mathrm{ZrO}_{6}$ octahedra are connected with each other by sharing their edges, although the polymerization degree is related to the molar ratio of initially added water to alkoxide. ${ }^{24)}$ The present results clearly indicate that the progress of the hydrolysis condensation process makes the structure of monomeric alkoxide more dense, so as to increase of the shared edge number of coordination polyhedra and that calculated shared edge length in structural model of about $0.26 \mathrm{~nm}$ is rather shorter than the estimated edge length of the regular zirconium octahedron. Consequently, the very distorted feature of zirconium octahedra is readily suggested in the structure of amorphous $\mathrm{ZrO}_{2}$.

Murase et al. ${ }^{5)}$ examined the crystallization of amorphous $\mathrm{ZrO}_{2}$ produced by sol-gel method at various conditions, and suggested that the crystallization behavior of amorphous $\mathrm{ZrO}_{2}$ strongly depends on the conditions of sample preparation. Therefore, it is difficult to determine which mechanism is actually significant in the formation of $t-\mathrm{ZrO}_{2}$ from amorphous $\mathrm{ZrO}_{2}$. Nevertheless, the present results, at least, suggest that it is quite unrealistic to identify the local ordering structure of amorphous $\mathrm{ZrO}_{2}$ to be responsible for the formation of $t-\mathrm{ZrO}_{2}$ as frequently discussed in the previous works. Moreover, the usefulness of AXS method coupled with least-squares technique has also been suggested as one of the most powerful tools for characterizing the structure of multi-component disordered system.

\section{Acknowledgments}

The authors want to thank Prof. H. Suito for his valuable discussion. They also thank Prof. M. Nomura, Photon Factory, National Laboratory for High Energy Physics for his kind help on the AXS measurements and Drs. W. R. Busing and A. H. Narten, Oak Ridge National Laboratory, for providing a general Fortran least-squares program. One of the authors (KS) wishes to thank to the Ishihara-Asada Research Fund through the Iron and Steel Institute of Japan.

\section{REFERENCES}

1) For example, S. Sakka and K. Kamiya: J. Non-Cryst. Solids, $\mathbf{4 2}$ (1980), 403.

2) K. S. Mazdiyasni, C. T. Lynch and J. Smith: J. Am. Ceram. Soc., 48 (1965), 372.

3) K. S. Mazdiyasni, C. T. Lynch and J. Smith: J. Am. Ceram. Soc., 49, (1966), 286.

4) R. C. Garvie: J. Phy. Chem., 69 (1965), 1238

5) Y. Murase, E. Kato and H. Matsumoto: Nippon Kagaku Kaishi, (1972), No. 12, 2239, (in Japanese).

6) R. Cypres, R. Wollast and J. Raucq: Ber. Dtsch. Keram. Ges., 40 (1963), 527

7) A. Clearfield: Inorg. Chem., 3 (1964), 146 
8) E. D. Whitney: Trans. Faraday Soc., 61 (1965), 1991.

9) J. Livage, K. Doi and C. Mazieres: J. Am. Ceram. Soc., 51 (1965), 349.

10) E. Tani, M. Yoshimura and S. Somiya: J. Am. Ceram. Soc., 66 (1983), 11

11) T. Mitsuhashi, M. Ichihara and U. Tatsuke: J. Am. Ceram. Soc., 57, (1974), 97.

12) R. L: Mozzi and B. E. Warren: J. Appl. Crystallogr., 2 (1965), 164.

13) Y. Waseda, E. Matsubara and K. Sugiyama: Sci. Rep. Res. Inst. Tohoku University, A34 (1988), 1.

14) A. H. Narten: J. Chem. Phys., 56 (1972), 1905.

15) H. Saito, H. Suzuki and H. Hayashi: Nippon Kagaku Kaishi, (1988), No. 8, 1571, (in Japanese).

16) C. N. J. Wagner, H. Ochen and M. L. Joshi: Z. Naturforsch., 20a (1965), 325.
17) D. T. Cromer and J. B. Mann: J. Chem. Phys., 47 (1967), 1892.

18) Y. Waseda: Novel Application of Anomalous X-ray Scattering for Structural Characterization of Disordered Materials, Springer-Verlag, New York, (1984).

19) International Tables for X-ray Crystallography, Vol. IV, The Knoch Press, Birmingham, (1974).

20) K. Furukawa: Rep. Prog. Phys., 25 (1962), 395.

21) R. Kaplow, S. L. Strong and B. L. Averback: Phys. Rev., 138 (1965), A1336.

22) J. D. McCullough and K. N. Trueblood: Acta Crystallogr., 12 (1959), 507.

23) G. Teufer: Acta Crystallogr., 15 (1962), 1187.

24) D. C. Bradly: Inorganic Polymers, ed. by F. G. A. Stone and W. A. G. Graham, Academic Press, New York, London, (1962), $410-446$. 